\title{
50 DIESEL EXHAUST AND LUNG CANCER MORTALITY: REANALYSIS OF A COHORT STUDY IN POTASH MINING
}

Matthias Möhner, Norbert Kersten, Johannes Gellissen Federal Institute for Occupational Safety and Health, Berlin, Germany

10.1136/oemed-2011-100382.50

Objectives To investigate lung cancer risk associated with occupational exposure to diesel motor exhaust in potash miners, while controlling for potential confounders such as smoking and previous uranium mining.

Methods Our investigation is based on a cohort study of nearly 6000 German potash miners, who were followed up from 1970 to 2001 (Säverin et al, 1999; Neumeyer-Gromen et al, 2009). The reanalysis focused mainly on the employment periods before potash mining, in particular uranium mining. Different statistical methods (Cox model, Poisson model, nested case-control study) were used to adjust for confounding. The exposure estimates were recalculated, lagging the exposure by 5 years. Exposure groups were defined by terciles of corresponding cumulative exposure estimates and occupational categories, where exposure is estimated by representative measurements of total carbon (TC) for different occupations. The highest TC concentration was measured for production workers, about twice as much as for other occupations.

Results The reanalysis revealed that while about $4 \%$ of all study subjects had worked earlier in uranium mines, $11.5 \%$ of later lung cancer cases did so. Ignoring study subjects with a history in uranium mining, the case-control study yields an OR of $1.40(0.39-5.09)_{95 \%}$ and $1.91(0.51-7.09)_{95 \%}$ for the second $\left(>2.1 \mathrm{mg} / \mathrm{m}^{3}{ }_{*}\right.$ year) and third tercile $\left(>4.2 \mathrm{mg} / \mathrm{m}^{3}{ }_{*}\right.$ year) respectively, in comparison to the lowest exposure tercile in the group of production workers.

Conclusions The study gives further hints for a dose-response relationship between exposure to diesel motor emissions and lung cancer risk. 